\title{
A Tourist Typology of Online and Face-to-Face Social Contact: Destination Immersion and Tourism Encapsulation/Decapsulation
}

\begin{abstract}
:
The sense of tourism encapsulation/decapsulation is increasingly determined by the level and type of connectivity enabled by advanced Information Communication Technology (ICT). This study explores tourists' online and face-to-face social contacts and their effects on travel experiences. A six-fold tourist typology is established, namely: Disconnected Immersive Traveller, Digital Detox Traveller, Diversionary Traveller, Dual Zone Traveller, Daily Life Controller and Social Media Addict. A contact-immersion nexus is also developed to indicate the attachment tendencies of different tourist types between their home and away zones. Theoretical contributions and practical implications are discussed.
\end{abstract}

Keywords: online social contact; face-to-face social contact; contact-immersion nexus; tourism encapsulation/decapsulation.

\section{INTRODUCTION}

Information Communication Technology (ICT) has been integrated into our daily lives, and tourism is not an exception (Wang, Xiang \& Fesenmaier, 2016; Buhalis, 2000). Traditionally, tourists try to escape during holidays keep a distance from their original social networks when they travel (Iso-Ahola, 1982; Krippendorf, 1986; Cohen, Prayag, \& Moital, 2014). Such physical and mental detachment contributes to their desire for relaxation and recovery when travelling (Lehto, 2013). The rapid development of technology connectivity enables people to dynamically engage with their home environment and networks, in real time regardless of distance and time (Buhalis \& Sinarta, 2019). The encapsulation and decapsulation of tourism must be reconsidered given the unavoidable intervention of the online presence.

The investigation of online social contact is still immature, considering the dramatic change of modern travel intensified by the emergence of social media platforms. Buhalis and O'Connor (2005) stated that technology developments have changed tourism greatly by revolutionising information gathering, communication, storage and dissemination. The technological mediatisation has broken the traditional social bubble for tourists by providing dynamic online communication channels (Jansson, 2002, 2013, 2018). The digital empowerment and the proliferation of smartphones have effectively merged tourists' network at home with the network at the destination. Hybrid social networks emerge, where tourists have simultaneous access to both online and physical networks. This presents tourists with a complex, functional and connected world. 
The rapid development and dynamic nature of technology determine that most well-established tourist studies have yet to consider online social contact as an important part of the tourist destination experience. There are numerous studies exploring tourist typology (e.g. Cohen, 1972, 1979b; Smith, 1989; Pearce \& Lee, 2005). However, few studies examine the rich behavioural patterns of social contact and relate them to tourists' destination immersion. How different kinds of social contact influence tourists' destination experience and their attachment to the destination/home remains unclear. Moreover, limited efforts have been made to consider online social contact together with face to face social contact in tourist typology studies. The lack of updated and accurate grouping regarding social contact also creates difficulties for practitioners to draw effective marketing strategies for diverse segments. Traditional tourism experience related theories, such as tourist immersion and experience mode were developed prior to the emergence of the digital world. Their explanation power and applicability among connected tourists are vague and therefore a refined examination of existing theories and tourists' emerging social patterns is required. This study aims to establish a tourist typology that considers both online and face-to-face social contact behaviours during travel. It also explores the destination immersive level for different tourist types. Chinese overseas tourists are targeted for the current study, not only because China is the largest outbound tourist market (UNWTO, 2017), but also due to the salient usage coverage of the Internet, e-commerce and social media (China Internet Network Information Center, 2017).

\section{LITERATURE REVIEW}

At the era of connectivity, online social contact has become a norm among travellers and greatly influences tourists' travel behaviour and experience (Buhalis \& Sinarta, 2019). Hitherto tourist studies have not considered online social contact as an important part of the tourist destination experience. Tourists are no longer isolated in a completely away zone when they travel, due to their connectivity with their original social networks. Tourists have the autonomy to decide whether, when and how to reach their home environment and what to share with their networks. Their online contact and interaction with home networks often influence their travel behaviour, experience and destination immersion level. This phenomenon opens a new era for tourism encapsulation/decapsulation research and deserves in-depth investigation.

\section{Tourism Encapsulation and Decapsulation}

The emergence of the Internet and new media intensifies the touristic experience and blurs the touristic texture of a place (Jansson, 2018). Jansson (2007) proposed the dialectic of encapsulation/decapsulation as a means for approaching the space-communication nexus in tourism. In his study, Jansson (2007, p.8) described: "the balance between being immersed in a liminal realm, and being hooked up to the world of routines, duties and ordinariness can be approached as a dialectical relationship between encapsulation and decapsulation". In the nexus, 
"the digital and mobile media provide resources for the intensification of touristic experience-a fulfilment of the encapsulation process" (Jansson, 2007, p.19). This approach includes technology-enabled multi-sensory experiences, personalised service design, specialised travel information, time-efficiency and sense of control (Buhalis \& Foerste, 2015).

The mediatisation can also enable the connection between tourists and their home social networks, break this capsule by abolishing the boundaries between tourism and everyday life, leading to decapsulation (Jansson, 2007). Cohen et al. (2015) explain that contemporary lifestyle-led mobility patterns illustrate a breakdown in conventional binary divides between work and leisure, and a destabilisation of concepts of "home" and "away". Jansson's (2007) nexus also identified three realms, namely: scripting, navigation and representation, within which new media can sustain and threaten the process of encapsulation. This work provides a useful theoretical base for the current empirical study by identifying how different forms of communication are interwoven and influence the activities and experiences of different tourists.

Prior to any empirical examination, an initial question that must be answered is how to identify a tourist's encapsulation/decapsulation status. Extensive studies investigated this phenomenon by providing evidence of tourists' destination immersion. Lash and Urry (1994) stated that immersive attitude refers to "a curiosity about places, people, cultures, and their historical and anthropological roots", "an openness towards and appreciation of cultural differences" and "an aspiration to understand the relative place of one's own society and culture in a broader global framework" (Jansson, 2007, p. 16). Immersive tourists aim to understand the social and cultural realities beyond ordinary tourist destinations. They connect to local social network and try not to reveal their identity as tourists (MacCannell, 1976; Maoz, 2006). In Csikszentmihalyi and Csikszentmihalyi's (1975) theory of flow, this immersive status is also described as the experience of complete involvement of the actor with his activity, in which the participant can be mentally and physically aroused, focused and engaged.

\section{Tourist Social Contact and Connectivity}

Being connected or not during travel has been well debated in tourist studies (Tanti \& Buhalis, 2017). As indicated in encapsulation/decapsulation research, the process of encapsulation/decapsulation involves different forms of interwoven communication that influence the activities and experiences of tourists. Therefore, understanding the role that social contact plays in tourist experience formation is essential to explore tourists' destination immersion.

Social contact, especially between tourists and hosts, is essential in the host-guest relationship (Maoz, 2010; Fan, Zhang, Jenkins \& Tavitiyaman, 2017). Social contact is originally described as the face-to-face contact among different individuals (Cusher \& Brislin, 1996; Yu \& Lee, 2014). Tourist social contact can vary depending on the occasions and participating groups. Choo and Petrick (2014) identified four kinds of groups involved in contacting tourists, namely: 
residents, other customers, service providers, and companions. Pearce (2005) recognized that the tourism context has three types of social contact, namely: tourist-local community, touristservice personnel, and tourist-tourist.

Tourist-host social contact has drawn considerable attention. Tourism provides a natural platform where tourists meet local residents and experience local cultures by interacting with local people. This kind of contact may vary among different tourists. Cohen (1972) developed a fourfold tourist typology according to the degree of contact, namely: organized mass tourist, individual mass tourist, explorer, and drifter. Building on the work of Cohen, Fan et al. (2017) explored tourists' contact with hosts by featuring the purposes, determinants, activities, intensity, impacts, and attitude of contact. Five types of tourists emerged accordingly, namely: dependents, conservatives, criticizers, explorers, and belonging seekers. In addition, the contact between customers and service providers influences the satisfaction and overall service experience of customers (Lovelock \& Wirtz, 2004). Travellers are able to affect one another indirectly, by being part of the environment, or directly through specific interpersonal encounters (Bitner, 1992; Rihova et al., 2015). In the tourism setting, Wu (2007) investigated tourist-tourist interaction incidents among Taiwanese tourists and the impacts on their travel experience.

As shown in Figure 1, with the rapid development of the Internet, tourists not only experience face-to-face contact with different people in the destination. They also interact digitally with other people, including families, friends, colleagues, service providers and even strangers, via various social media platforms whilst traveling. Tourists can interact with their online and offline environments simultaneously and share suggestions, opinions, questions and memories related to their journey. It is crucial therefore to explore tourists' online and face-to-face social contact behaviours and their travel experiences.

\section{Insert Figure 1 Here}

Connectivity has become a passionately discussed topic in tourism experience (Kirillova \& Wang, 2016). Attention restoration theory (ART) has provided an insightful arguing aspect (Lehto, 2013). Restoration is "the process of renewing or recovering physical, psychological and social capabilities that have become depleted in meeting ordinary adaptational demands" (Hartig $\&$ Staats, 2005). ART indicates how individuals are motivated by their desire for psychological restoration to seek connection with the natural environment (Kaplan, 1995). To achieve restoration, one must enter an environment that can elicit involuntary attention, be free from any mental activity requiring directed attention, sense the connectivity and scope of the environment and assure that the environment has the opportunity to function as required (Kler, 2009). Kaplan's theory (Kaplan, 1995; De Botton, 2008) suggests that being away should be both physical and psychological. Travelling to a different geographical location per se is not a real restoration, if daily routines and tasks remain accessible, such as worrying about work, the wellbeing of family members and other daily issues. Building on the ART, Kirillova and Wang (2016) explored the role connectivity plays in facilitating tourists' recovery. Results indicated 
that, frequency of work-related social presence acts as a negative moderator. Quality of work and non-work social presence are positive moderators between destination restorative qualities and vacation recovery. Tourists are therefore understandably not always keen on getting connected during their travel, depending on structural issues, personal preferences and interpersonal influences (Dickinson, Hibbert, \& Filimonau, 2016). Hence, different online and face-to-face contact preferences may lead to different travel experiences.

\section{CONCEPTUAL FRAMEWORK FORMATION}

This study aims to develop a tourist typology that considers both online and face-to-face social contact behaviours during travel. A typology is derived conceptually and deductively (Marradi, 1990; Nickerson, Varshney, \& Muntermann, 2013). In the conceptual typology approach, a typology of categories is based on a theoretical idea or model. The researcher can define or further refine an ideal type that is used to examine empirical cases in terms of how much they deviate from the ideal (Weber, 1949). The term typology is usually restricted to a system of conceptually derived groupings. Typologies normally cope with multidimensional classifications, rather than simple unidimensional classifications and imply themselves to deal with complex theoretical models (Bailey, 1984; Doty \& Glick, 1994).

A robust theoretical framework is required to develop a systematic typology regarding tourist online and face-to-face social contact behaviours. As delineated in the research objectives, at the core of this typology, online and face-to-face social contact composes the leading conceptual logic which leads the categorisation process. A supporting conceptual logic is included to provide nuanced differentiating evidence and supplementary information for the current typology with reference to the existing theories. The supporting conceptual logic holds the explanatory power of tourists' behavioural patterns and is able to provide insights to understanding tourists' destination immersion. The selection of the theories in this logic is based on the literature (Fan et al., 2017), which argued that, tourist social contact is strongly determined by travel motivation, and is closely related to the pursuit of familiarity and novelty in the destination (Cohen, 1972) and the quest of centre (Cohen, 1979b). As a result, three well-established theories are included to portray and interpret the tourist behavioural patterns in the current study, namely: travel motivation, tourist destination role and experience mode.

In tourist immersion studies, motivation is considered as an essential determinant (MacCannell, 1976; Lash \& Urry, 1994; Maoz, 2006; Huang et al., 2018). According to push and pull theory, people travel because they are "pushed" into making travel decisions by internal, psychological forces, and "pulled" by the external forces of the destination attributes (Crompton, 1979). IsoAhola (1982) developed a seeking escaping tourism motivation theory. The Travel Career Ladder (TCL) and Travel Career Pattern (TCP) motivational models were based upon Maslow's hierarchy of needs and the conceptualisation of psychological maturation towards a goal of selfactualization (Ryan, 1998). Pearce introduced five consisting motivation levels: relaxation needs, 
stimulation (Safety/security) needs, relationship needs, self-esteem \& development needs, and fulfilment needs (Pearce \& Lee, 2005).

As a fundamental work of the tourist-host social contact studies, Cohen (1972) developed a fourfold tourist typology. According to the degree of familiarity and novelty in travel, tourists are categorised into four roles: organized mass tourist, individual mass tourist, explorer and drifter. To relate tourism with pilgrimage, Cohen (1979b) also argued that tourists travel with a quest for the centre. The centre is not necessarily the one geographically central to the everyday community. According to the touristic experience and its alternative forms of relationship between a modern person and various centres, five modes of tourist experiences are identified: recreational, diversionary, experiential, experimental and existential modes, from restoring physical and mental power with limited commitment to travel to attaching to an elective external centre. It was also noted by Cohen (1979a) that various modes of tourists were presented in an ascending order from most superficial to most profound in experience. The concept of quest for the centre is useful to help understand tourists' immersion in a destination.

Figure 2 shows the conceptual logic of the current tourist typology. The leading conceptual logic of this typology is tourist social contact, representing the empirical level of attributes, entitled behavioural pattern, including online and face-to-face social contact with different parties. The second layer is the supporting conceptual logic, consisting of three theoretical bases from social and psychological contexts identified from the literature review, namely: travel motivation, tourist destination role and tourist experience mode. These two layers of logic theoretically determinate the types, dimensions and characteristics of this typology.

\section{Insert Figure 2 Here}

\section{METHODOLOGY}

The study adopts an interpretivism paradigm. Interpretivists believe that reality is created by individuals in a society (Rossman \& Rallis, 2003) and understand a phenomenon as it is from the perspective of individual experiences. Therefore, an in-depth, face-to-face interview method was adopted as the main technique to generate rich primary data.

Qualified informants were Mainland Chinese tourists who had overseas travel experience in the last two years and used online platforms to contact others during their trips. The interview protocol included four parts. Firstly, respondents were asked about their recent travel experiences during which they used online platforms to contact people. Secondly, informants were asked to recall their online and face-to -face contact experiences, including contact frequency, contact channels, contact groups, contact activities and perceived value during contact, respectively. Thirdly, interviewees were inquired about their travel motivations and pursuit of authenticity in that trip. Finally, informants were asked to provide their demographic information. 
Purposive sampling was firstly used to determine eligible respondents, in accordance with the professional judgement of the researchers. Secondly, by following snowball sampling, respondents were asked to invite people in their social network, who were qualified for this research. Diversity in demographics, such as gender, age range, marital status and income level, was considered in selecting informants to ensure the inclusion of different demographics. The interviewers stopped inviting new informants when information saturation was reached. A total of 51 interviews were conducted. The data analysis indicated that dimensions and patterns stabilised at the 25th informant and the remaining 26 informants did not provide much substantive changes to the codebook. Twenty-one interviews were conducted face to face, and 30 were conducted via online face-to-face video calls. Each session lasted between 18 and 60 minutes, with an average length of 40 minutes. All interviews were recorded and transcribed. Interviews were conducted in Mandarin and then translated into English. To ensure the accuracy and credibility of translation, two professional language editors (Mandarin and English) were consulted during the translation process.

Table 1 shows that, among the 51 informants, 37 are female and 14 are male. Moreover, $64 \%$ of informants are between 25 and 39 years old and 46 out of 51 hold university degrees or above. Fifteen participants are employed as managers and administrators, and 14 are professionals. $42 \%$ of participants have a monthly household income ranging from 20,000 RMB - 39,999 RMB and $47 \%$ are single. This demographic pattern shows great consistency with the profile of the general Chinese outbound tourists released by the China Tourism Academy (2018). It highlights that young generations, born in the 1980s and 1970s, with high educational level, dominate the outbound tourist market. Meanwhile, female travellers occupy $60 \%$ of the market. With regard to outbound travel frequency, $76 \%$ of the interviewees travel abroad once or twice per year and $16 \%$ travel 3-4 times every year. Their travel destinations vary from short-haul ones, such as Korea, Japan and Southeast Asia countries, to long-haul ones such as US, Mexico, Sweden and New Zealand. The most frequently used online social platforms reported by informants were WeChat, QQ, and chat forums in Ctrip, Booking, Mafengwo, Qyer, Taobao and TripAdvisor.

\section{Insert Table 1 Here}

To systematically analyse the data and to capture the underlying meanings the narrative data delivered, both thematic and paradigmatic data analysis approaches were involved. Initially, thematic content analysis was conducted on textual data from the 51 transcripts to identify the main themes under each attribute. The NVivo 11 software was used to code the transcripts technically. During coding, meaningful units in participants' transcripts were captured and utilised to formulate key themes regarding the respondents' full range of information on social contact and travel experience.

Based on the themes, paradigmatic content analysis was conducted to capture the typology of tourists, online and face-to-face social contact patterns, and the destination immersive level of different tourist types. Paradigmatic content analysis is a methodological approach that has 
gained popularity in the social sciences in the last 30 years. Yet, this method of inquiry has been relatively neglected by tourism scholars (Mura \& Sharif, 2017). Although thematic analysis is a well-established and most popular strategy in qualitative research, it may silence important aspects of interviewees' accounts, namely their intrapersonal and interpersonal relationships due to the surface structure, coding approach and descriptive nature (Mura \& Sharif, 2017). Moreover, some patterns in findings could not be fragmented into thematic categories (Riessman, 2001). Paradigmatic analysis is the analysis of paradigms embedded in the text rather than on the surface structure (Chandler, 1994). It relies on paradigmatic cognition, a thinking skill that humans primarily use to organise experience as ordered and consistent. Paradigmatic mode of knowing attempts to fit individual details into a large pattern (Kim, 2015). As stated by Polkinghorne (1995) and Kim (2015), paradigmatic analysis can describe the categories or typologies while paying attention to the relationships among categories; uncover the commonalities that exist across the multiple sources of data; and produce the general knowledge from a set of evidence found in a collection of stories. This analytical method is widely used to explore the dynamic complexity of experience and relationship studies (Flick, 2014). While this is the approach that is commonly used in tourism, few studies have clarified the theoretical basis of the analysis. There are a range of examples of this type of content analysis in tourism research (Higham \& Hinch, 2002; Gibson, Willming \& Holdnak, 2003). By applying this analytical method, the tourist typology and destination immersive level of different tourists are not generated from the direct quotes or any particular text units. These are based on the identified themes, behavioural patterns and perceived experiences across different interviewees.

To ensure the trustworthiness of the qualitative study, the naturalistic inquiry approach principles suggested by Lincoln and Guba (1985) were followed. Credibility, transferability, dependability and confirmability were assessed. With regard to credibility, the techniques of triangulation, peer debriefing and member checks were applied. Firstly, on the basis of the data triangulation (Denzin, 1978), informants were recruited from multiple sources and channels (purposive and snowball samplings). The interviews were conducted at multiple times (between April and September 2018) and places, with informants from different cities across China. Investigator triangulation was also applied in addition to data triangulation. All authors regularly conducted intra-team communication to ensure the accuracy and credibility of the results. Theory triangulation was reflected by considering multiple perspectives during data analysis (Denzin, 1978). Multiple theories, such as travel motivation, tourist destination role and experience mode, were considered to ensure a robust portrait and profile for each tourist type. With regard to peer debriefing, two faculty members with research expertise in tourist experience and behaviour studies from two different universities in the UK were asked to be the disinterested peers. They debated with the research team during the stages of interview protocol design, codebook structure build-up and tourist typology discussion. Member checks were achieved by randomly selecting five transcripts, their summarised characteristics and the tentative tourist types they belong to. These were sent back to the corresponding informants to ensure the correct interpretation. Research transferability was also considered by providing a detailed description, including all versions of the interview protocols, informants' socio-demographic information, 
features identified in each attribute and characteristics for each tourist type. This approach enables future users to perform an empirical transfer of the current findings in other contexts or in the same context at a different time. As two individual coders were separately and simultaneously performing the coding, the dependency of the coding results was examined by the coders' interactive and iterative discussion. Finally, with regard to confirmability, an audit trail, including minutes of research design discussion, interview audios, transcripts, NVivo files, process notes and authors' reflexive journals, was well kept to confirm the entire research process and procedures.

\section{FINDINGS}

\section{Tourist Typology of Social Contact}

Based on the 51 interviews, six tourist types are generated according to their unique behavioural, social and psychological patterns identified in the conceptual framework, including travel motivation, online social contact, face-to-face social contact, tourist destination role and tourist experience mode. The following depictions attempt to portray each tourist type by delineating its behavioural characteristics (Figure 3). The six tourist types are as follows: Disconnected Immersive Traveller, Digital Detox Traveller, Diversionary Traveller, Dual Zone Traveller, Daily Life Controller and Social Media Addict.

\section{Insert Figure 3 Here}

\section{Disconnected Immersive Traveller}

The Disconnected Immersive Traveller is not connected and inactive in sharing, co-creating and interacting with others in the online world. This behavioural characteristic has extended from their daily life to their travel. The inactive online status may result from their personal privacy concerns or their own "old-fashioned" communicational habits. "I will not sacrifice my personal privacy to get free WIFI in return” (Informant 7, male, 30-34, professional). "I think it's my personality. I still prefer to meet people and have face-to-face communication nowadays if possible" (Informant 3, male, 25-29, clerk). When travelling, they have minimum contact with their home social groups. "I was busy exploring the destination. Chatting online in a destination is a waste of time" (Informant 31, female, 40-49, manager/administrator). In comparison with their original social group, they tend to have an intense interaction with the people they meet in the destination. Their contact groups cover travel companions, other tourists, service personnel 
and residents. Their main travel motivations are self-improvement, understanding otherness and experiencing local culture.

"Most of the time during my travel, I love to chat with strangers. I can hear many life stories which are entirely different from mine. Some of them may have been here many times, and the others for the first time. They share valuable and interesting information with me. I love to do this very much.... Recently during my trip in Indonesia, I met a guy from Germany who is addicted to diving. .... A young girl just resigned from her job and decided to travel for 3 months.... A couple took a 4-month leave and travelled around the world..." (Informant 3, male, 25-29, clerk).

\section{Digital Detox Traveller}

The intensified and overwhelmed use of the Internet might exhaust people mentally and physically. To recover, some tourists prefer to switch off their smart phone and disconnect with their original world (Neuhofer \& Ladkin, 2017). Digital Detox Travellers believe that this decision is the only way to recover and enjoy the holiday entirely. In comparison with the Disconnected Immersive Traveller, who is inactive in online activities whether during travel or in everyday life, Digital Detox Travellers use the Internet to communicate heavily with others at home. However, they consciously and proactively control their exposure in their home environment during travel to encapsulate themselves within the journey. Disconnection from their home enables them to appreciate travel and further interact with their travel companions, the local people or even themselves.

"I do not normally contact my family, friends or colleagues during my travel, as I need more time to enjoy the beautiful scenery and the companion of my husband" (Informant 17, female, 30-39, student). "I do chat online with my friends a lot everyday but not when I am travelling.... Get away and leave me alone..." (Informant 12, female, 25-29, professional).

The Digital Detox Traveller shares similar face-to-face social contact at the destination to the Disconnected Immersive Traveller. Digital Detox Travellers tend to build a strong attachment with the destination.

"'Game of Thrones' is my favourite. Our B\&B had a unique view of the Mediterranean and the ancient city Dubrovnik, where the drama was filmed. When we had a tour there, we hired a personal tour guide who was also a body double in that drama!" (Informant 17, female, 30-39, student)

\section{Diversionary Traveller}

Diversionary Travellers have a low contact level with either their home or destination. This tourist type maintains a low level of communication with their original social network, but they have considerably more contact via online platforms than the first two types. Informants reported that they check and respond to messages during their trips, when they have fragments of time. They get online during a break between attractions, when resting in their room or, most 
importantly, when they have free access to the Internet. Maintaining an active online status is not a main concern during their travel. However, occasional communication with their family and friends at home can be a bonus for their travel experience. "I use free WIFI to contact my friends and family. I am not eager to get online all the time. It is fine to have a free WIFI access; if not, it does not matter much" (Informant 9, female, 50-59, manager/administrator).

They have limited face-to-face contact in the destination, especially with local people. "I would not proactively have contact with local people, except when I urgently need some travel information or services" (Informant 13, female, 25-29, manager/administrator). A Diversionary Traveller travels to relax, recover and escape from the daily life. "I felt that I left the extremely busy and stressful working environment at home. The only thing I would like to do is to relax and find the peace of mind" (Informant 22, female, 25-29, student/part-time clerk).

\section{Daily Life Controller}

A Daily Life Controller keeps a frequent contact with their original social group when travelling. They like to actively participate in their daily life activities, even while on a holiday. The development of the Internet helps them maintain a desired presence in their original life. One important reason for these tourists to maintain a high level of interaction online is responsibility. This is particularly the case for young parents or entrepreneurs running their own business.

"I do an instant video chat via the camera with people at home frequently during my trip. My son is only 2 years old and I need to make sure that everything is fine at home. Otherwise, I would not choose to travel for a break. I feel secure and less anxious with the connection with home" (Informant 8, female, 30-39, professional).

"I have several projects in hand and need to liaise with clients all the time. Due to this reason, I need to make myself available and connected whenever they need me" (Informant 2, female, 25-29, manager/administrator).

Contacts with their original social groups can reduce these tourists' travel anxiety and create a sense of security, which may allow them to travel at the first place. This group holds a positive view towards online contact during their travel. "Being connected makes me feel comfortable and confident. I cannot enjoy my travel without getting in touch with my familiar social circle" (Informant 43, male, 40-49, manager/administrator). Given the high level of online presence, the fragments of time may be insufficient for them to manage the issues at home. They have to sacrifice some travel time, dedicate time to connect or even pay for roaming. They generally travel with a flexible itinerary to allow any contingency plan. When they are free from online communication, they may spend some time with the tour guides, travel companions, service personnel and even the residents to get a touch of the destination and their holiday mood.

"I chatted with local people when I had time. For example, the Uber driver we met in the US was very talkative, introducing quite a few interesting spots for us along the journey. I can also learn the local social culture by receiving different kinds of services" (Informant 8, female, 30-39, professional). 
The constant communication with family, colleagues and clients blurs the boundaries between home and destination. They remain largely decapsulated due to the co-presence of reality and holiday. They travel to seek relaxation, recharge and recovery from the daily routine. "I think travel is a process of recharge for me. My multiple duties and roles make me feel exhausted in my everyday life. I need some excitement and recreation to carry on" (Informant 2, female, 2529, manager/administrator). Connectivity is a critical factor of peace of mind and enjoyment. Having access to internet is fundamental to their enjoyment.

\section{Social Media Addict}

The Social Media Addict maintains a high level of social media presence when travelling. They post pictures of sceneries, food, people, selfies and other material frequently. In more severe cases, they stream their trips live.

"I posted around eight to 10 travel news on my page every day in my trip early this year. I even do a live broadcast to my family members and friends. I would like to share whatever I see with them and encourage them to come if they have opportunities in the future" (Informant 33, female, 50-59, retired).

Social Media Addicts tend to contact with different people in the destination, such as service personnel, residents and other tourists. Hashtags and geotagging are commonly used techniques to find people locally. This kind of contact however remains service-oriented and superficial. Their social circles are part of the journey and the journey becomes a conversation in real time, sharing and co-creating the experience.

"It is very efficient to use geotagging functions to find what you need in the destination. For example, I often use geotagging in my social media to ask for local tour guides or peer tourists who can share the travel cost with me" (Informant 5, female, 25-29, craft and related workers).

Travelling for them serves as an opportunity to share their feelings and travelling experiences, achieve a self-fulfilment and even show off among their original social group. Their travel happiness mainly comes from sharing and co-creation, as well as the appreciation from their social groups. They use social media platforms such as Instagram and Facebook to record every moment of their trips.

"When I posted some travel photos online, my friends liked them and commented on them. Of course, I like comments better as I can respond back. I like such kind of interaction as we all talk about some happy things of travel. I admit that this is kind of showing off in my social groups.... When people travel, they are in an ultimate condition. I want to show the best of me to my friends" (Informant 34, female, 30-39, manager/administrator).

They send pictures to their families and friends, post several pictures on their personal social media pages describing their feelings and even broadcast live wherever they go. Collecting likes, receiving feedback from their networks and interacting with their social groups create fun to their journey. Travelling per se is happiness but sharing this happiness with people is even better. 
Thus, the joy activated by travel and co-created with their original networks is their biggest achievement.

\section{Dual Zone Traveller}

Dual Zone Travellers carry the characteristics generated from a high level of social contact online and on site. This group is determined to manage their original and away worlds simultaneously. They keep a high level of interaction with their original social network, without abandoning the opportunity to have a contact with local people and their travel companions. They tend to maximise their energy level in the trip and remain active in both zones.

"I don't think I have to entirely sacrifice one side to fully enjoy the other. When I travel, I can interact with locals and try to fit in their culture. When I chat with my friends and colleagues, I feel like I am still around. I can change my role quickly between the two zones. I enjoy this kind of involvement in both sides rather than isolating myself entirely for a week" (Informant 29, female, 3039, hunting for jobs).

They contact their friends and relatives, post destination pictures and even work if necessary, similar to the Daily Life Controller and Social Media Addict, but not to that extreme. Meanwhile, they try to explore the destination as much as they can by interacting with different groups of people on site. They enjoy online and face-to-face social contact and can transit between their original worlds and destinations with little hassle.

"I am a freelance designer and work on some small projects. I do not have a fixed itinerary when traveling. When I receive jobs in my journey, I will just do the work somewhere at the destination. I feel this is my lifestyle. I do not have a clear cut-off line between daily life and travel" (Informant 46, female, 30-39, freelancer).

Dual Zone Travellers enjoy the happiness of travel and stay on top of their home environment. However, they sacrifice a portion of destination immersion to keep in touch with their original life. This behavioural pattern is common among modern tourists who have responsible jobs and are confident with electronic media. Digital nomads and teleworkers are often among these travellers, working in internet cafes or shared working spaces during the travel (Richards, 2015).

\section{Online Versus Face-to-Face Social Contact of Different Tourists}

An axis is developed to provide a direct view of online and face-to-face social contact levels for different tourist types. Figure 4 shows that, albeit with different reasons, Digital Detox Traveller and Disconnected Immersive Traveller have a relatively low level of online social interaction but a high level of face-to-face social contact. Diversionary Travellers tend to have some but limited online or face-to-face communication with people due to their low commitment with either their home or destination. The Social Media Addict and Daily Life Controller have a high level of online interaction with their social network for different purposes but allocate less time and 
efforts to face-to-face contact. Dual Zone Travellers keep a high level of online and face-to-face social contact. The high presence of original and away zones maximises the association with their original network and their exploration in the destination.

\section{Insert Figure 4 Here}

\section{Contact-Immersion Nexus}

Tourists' destination immersion status, as one of the research objectives of this study, is also evaluated. A contact-immersion nexus (Figure 5) has been established to describe the tourism encapsulation/decapsulation of different tourists.

\section{Insert Figure 5 Here}

In this nexus, the Daily Life Controller is the most attached to their home zones. They maintain a high level of online presence during their travel due to responsibilities at home. This constant connection with their original social network determines their low level of encapsulation in the destination and their holiday mode. Many business travellers are in this type and stay detached to the away zone. Although the Social Media Addict shares a similar online and face-to-face contact pattern to the Daily Life Controller, their destination immersive level is higher. The findings indicate that the Social Media Addict shares travel moments online with their original social group. Although they spend a great portion of their travel time online, the things that they share may reinforce their travel experience (Jansson, 2007). Considering their inactive presence in the online world, Disconnected Immersive Travellers are encapsulated in the destination away zone and have intensive contact with different groups of people. They enjoy the original way of travelling and explore the destination through experience and interactions. They appreciate the mental, physical and social refinement activated by travel. Digital Detox Traveller shares similar contact behaviour to Disconnected Immersive Travellers at the destination. However, Digital Detox Travellers adopt this behaviour consciously to detoxify from their overwhelming online connectivity. They are the most destination-encapsulated type among all tourist types, due to their internal desire to fully immerse into a destination.

As shown in Figure 5, the Diversionary Traveller and Dual Zone Traveller are off the track and in the middle position of the nexus. The Diversionary Traveller has considerably less online social presence during their travel than the Daily Life Controller and Social Media Addict. However, it does not mean that they have an active face-to-face contact with others at the destination. Their low commitment to the home and away zones restricts their interactions with others, either online or face-to-face. The Dual Zone Traveller tends to have a high social presence in online and face-to-face environments. As such, they have a relatively higher immersive level than the Daily Life Controller, Social Media Addict and Diversionary Traveller while maintaining an equal attachment to their home zone. This group of tourists maximises the 
connectivity with different parties in both their original networks and the destination. This tourist type is newly emerged and rapidly growing with the development and wide usage of the Internet. However, their immersive level cannot exceed those of Digital Detox Traveller and Disconnected Immersive Traveller due to their shared amount of attention at the destination.

Tourists may switch their roles among the six types across different trips and at different stages of their lives, due to different motivations and travel conditions for each trip. For example, a young mother, of a 2-year-old son, can be a Daily Life Controller at the current stage but may switch to a Digital Detox Traveller after her son gets into college 17 years later. Thus, the proposed typology should be understood as dynamic, context based and trip grounded, rather than static or permanent. This typology also shows demographic patterns across different types. Interestingly, female are dominating the Diversionary Traveller and Social Media Addict types. Over half of the 50 years old or above informants belong to the Diversionary Travellers. However, Digital Detox Travellers and Dual Zone Travellers are relatively young. It is argued that tourists' demographic patterns across types are closely related to their ICT adoption and travel motivations.

\section{DISCUSSION AND IMPLICATIONS}

Different tourist types were compared with reference to established literature. The Disconnected Immersive Traveller and Digital Detox Travellers are mostly experienced international travellers and motivated by self-fulfilment and self-development needs, such as self-improvement, selfreflection and self-detoxifying. However, the Daily Life Controller and Social Media Addict often hold less overseas travel experience and are mainly motivated by their physiological needs, for relaxation, recovery and escape. This motivational pattern is consistent with Pearce and Lee's (2005) TCL, which argues that travel motivation is dynamic and multilevel. Along with the accumulation of international travel experience, travel motivations may shift from the basic relaxation need to fulfilment.

Cohen's (1972) tourist destination roles are also reflected in the findings. In particular, Digital Detox Traveller and Disconnected Immersive Traveller have contact with the local people as much as they can due to their high commitment in the destination. Their social behaviour fits the profiles of the explorer and drifter in Cohen's description. Comparatively, the Social Media Addict and Diversionary Traveller tend to have a minimum degree of interaction with the locals and fit into the portraits of organised and individual mass tourists. Although the Daily Life Controller also has limited contact with the local people, they are more likely to be individual mass tourists than organised mass tourists. They can enjoy a flexible itinerary to manage any contingency plan online. The Dual Zone Traveller is also active in interacting with the local people, but only to a certain extent, due to their dual active status in online social contact. They are committed to the home and away zones, but their commitment cannot reach maximum levels in either zone because they need to free themselves and jump out of a commitment from one 
zone to the other without any hassle. Thus, they are identified to be similar to an individual mass tourist or explorer.

With regard to tourist experience, the contact-immersion nexus is highly consistent with Cohen's (1979b) theory. The Daily Life Controller and Social Media Addict are highly committed to their original zone during travel, and their "spiritual centre" is their original culture centre. Their travel experience is largely recreational to restore physical and mental power for their daily life. The Diversionary Traveller reports a low commitment to either the home or away zone. As described by Cohen (1979b) in his tourist experience mode, tourists with diversionary mode seek a mere escape from boredom and meaninglessness of routine to the forgetfulness of a vacation. Therefore, they are not keen to contact their home social network during travel. Similarly, in the current study, this type of trip may heal the body and sooth the spirit but does not recreate. The Diversionary Traveller is spiritually uncommitted with their original culture centre, so their trip is not rewarding in nature. They are also called centre-less people (Cohen, $1979 b$ ) seeking for a meaningless pleasure in travel. Thus, they are not inspired to contact anyone either at home or in the destination, either online or face to face. They are also demotivated to immerse deeply into the destination or interact actively with others. The Digital Detox Traveller's and Disconnected Immersive Traveller's travel experiences are largely experimental and existential because their spiritual centres are elective, that is, destinations. In this modern pilgrimage, they fully immerse in elective centres and explore as much as they can for the enlightenment, power or communitas that are activated by travel. The Dual Zone Traveller is an exception from Cohen's (1979b) experience mode. This group of tourists looks for meaning and authenticity in the life of others when travelling, while maintaining their faith on their original culture. They can be called culture dualists or digital nomads, which are hardly reflected in previous literature. This is a unique phenomenon introduced by the rapid development and wide usage of the Internet. Their unique feature is being attached to the home and away zones simultaneously.

The findings provide implications for practitioners during the planning, marketing and management stages of tourism development. This typology may inform tourism product planners, marketing teams and local operators to facilitate the formulation of tailor-made products for diverse tourist markets. Understanding the types of travellers that a destination or a tourism and hospitality organisation attracts can determine the types of facilities and services offered. For instance, the Social Media Addict maintains a high level of social media presence and instantly shares travel experiences. They are naturally becoming destination ambassadors and advocates in their own social network. To boost their promotional effect, destinations should facilitate eword-of-mouth, by providing free WIFI or $5 \mathrm{G}$ connectivity, initiating check-point campaigns and encouraging sharing of pictures, personal experiences and service products to their social network as well as posting review comments on third-party review websites. Generation Z tourists may easily fit in the types of Daily Life Controller, Social Media Addict and Dual Zone Traveller, as they are the first cohort to have had Internet technology readily available at a very young age. Destinations targeting this group should take actions to accommodate their online 
needs during travel. Facilities can include technological infrastructure, such as connected digital rooms with appropriate functionality as well as marked areas where travellers can meet and interact both physically and digitally. This is already evident in hostels and modern hi-tech hotels such as Citizen M, which often attract a higher percentage of digital nomads, such as Social Media Addicts and Dual Zone Travellers. They provide lounge activities that facilitate both physical and digital connectivity, with a range of amenities to meet the requirements of these segments. Similarly, Disconnected Immersive Travellers and Digital Detox Travellers may need facilities that encourage face-to-face interaction with locals. Art and culture galleries as well as physical spaces that have board games may support meeting and co-creating experiences with other travellers or local people. Facilitating the needs and requirements of travellers increases satisfaction and advocacy as well as attracts more travellers with similar profiles.

\section{CONCLUSION}

This study refines the understanding of destination immersion phenomenon in tourism. It applies a qualitative research approach with 51 in-depth interviews. A six-fold tourist typology is developed in accordance with tourists' online and face-to-face social contact during travel, namely: Disconnected Immersive Traveller, Digital Detox Traveller, Diversionary Traveller, Dual Zone Traveller, Daily Life Controller and Social Media Addict. Each tourist type represents a unique profile that reflects their social, psychological and behavioural patterns in the destination. A nexus indicating tourists' attachment tendency to home and away zones is also established.

By identifying the six tourist types, this study argues that tourists' destination encapsulation/decapsulation level varies with their dynamic online and face-to-face social contact behaviours. Tourists are encapsulated if they get immersed into the destination, maximise their social interactions with people on site and concurrently minimise their online contact with their home network. In contrast, tourists tend to be decapsulated if they constantly contact their home social network during travel and have limited interactions with people on site.

Not all tourists are low in one zone and high in the other. This finding challenges the traditional binary Home-Away Zone by proposing two additional tourist statuses and opens a new perspective to understand tourists' travel experience. The low online presence does not automatically lead to an active face-to-face contact with others at the destination for the Diversionary Traveller. Their low commitment to the home and away zones restricts their interactions with others, either online or face-to-face. The Dual Zone Travellers remain closely attached to both zones with sufficient connections online and on site. The Dual Zone Travellers have a high social presence in online and face-to-face environments. As such, they have a high immersive level in the destination while maintaining attached to their home zone. In addition, besides the traditional home zone and away zone, tourists may also enter an online zone which is enabled by the extensive use of online platforms during the trip. In this study, though in an implicit way, some informants were found to closely attach to their online zone emerged during 
their travel. Travel for them acts as a media and provides them the context of communication and sociality. They discussed the travel related topics, including itinerary, travel tips, destination hidden gems etc. Some of the contacts terminate when tourists finish that particular trip, whereas the others continue their connections even after the trip. A future research targeting on the nuanced exploration of this unique zone is encouraged.

This research supported that online social contact could lead to both destination encapsulation and decapsulation for tourists, which is consistent with the previous literature (Jansson, 2007). In general, though for most of the cases, social interactions could commonly drag tourists from the away zone to the home zone. Tourists can also benefit from intensification of the touristic experience by sharing and reinforcement, release of the anxiety and discomfort induced by being away from home and obtain real time assistance and en-route trip planning. All the above can help with the process of encapsulation for tourists. However, despite of this, the effect tends to be limited and could hardly reach the high immersive level. This is reflected in Figure 5, indicating that although the Social Media Addict and Dual Zone Traveller have the chance to interact online with their original social network and benefit from the technology enhanced tourist social experience, their overall travel experience is still not as immersive as that of Disconnected Immersive Traveller and Digital Detox Traveller. It argues that a high level of destination immersion still requires a social liminality/distance from their original network to allow the encapsulation status. Considering the extensive use of ICT nowadays, it is important to realise that the new online media can sometimes work as an effective way to ensure a good travel experience and to release the travel discomfort, but it can rarely work as a stimulator of boosting destination immersion and pushing it to a high level. This finding corresponds to the social costs of ubiquitous connectivity (Kushlev \& Proulx, 2016) and supports the mediatized deterritorialization process (Jansson, 2002; 2007; Andersson, 2012; Fast \& Jansson, 2019).

To conclude, this study is the first attempt to portray tourists' behaviour in accordance with their online and face-to-face social contact when travelling. The emerging tourism phenomenon in the seamless connection era is interpreted with reference to different theoretical supports. This work supplements existing typology studies of tourist behaviour, which mainly consider the face-toface interactions between tourists and different social groups. Such typology reveals a series of complex behavioural patterns of modern travellers. The contact-immersion nexus developed in this research provides a new aspect for understanding tourists' destination immersion in a wellconnected world. The sense of destination immersion is also refined to further address the emerging experience aroused by the Internet. The social experience of tourists is an important realm from both sociological and anthropological perspectives. However, empirical studies in this area are still limited in tourism. The rapid development of new media saturates the social experience of tourists and challenges the traditional way of evaluating tourists' destination immersion. This study contributes to the destination immersion studies by introducing a new social texture into the quest, that is, the co-presence of home and destination or online and faceto-face social contact. This work also progresses the encapsulation and decapsulation theory and 
space-communication nexus proposed by Jansson (2007) by identifying different tourist types and fitting them into the nexus in sequence on the basis of their features.

As is the case with most research, this investigation was not without its limitations. First, the study was conducted among Chinese outbound tourists. Though diversity in demographics was considered in selecting informants, the result should be considered within the specific culture context. Meanwhile, the level of online connectivity is influenced by the local data policy and package, and the popularity of different apps and devices. Future research is hence encouraged to test this tourist typology in other research contexts. Second, this study considers the entire trip as the typology context, so the temporary status that could be generated and the changes of tourists' immersive level during one trip are not elaborated. Moreover, this study merely considers the effect of online social contact which excludes other functions that online technology may have for tourists, such as scripting, navigation and representation (Jansson, 2007). Hence, the dynamic nature of tourist destination immersion and the non-social aspects of technology facilitated tourist experience can be further explored in future studies. Last, as different tourist typologies are strictly framed by the logic and framework applied in each study, future investigations are encouraged to involve different theories to portrait tourists from diverse perspectives.

\section{REFERENCES}

Andersson, M. (2012). Media and Migration through the Lens of Mediatization and Transnationalism. In Communication and Community: The annual ICA Conference.

Bailey, K. D. (1984). A three-level measurement model. Quality \& Quantity, 18(3), 225-245.

Bitner, M. J. (1992). Servicescapes: The impact of physical surroundings on customers and employees. The Journal of Marketing, 57-71.

Buhalis, D. (2000), Information Technology in Tourism: Past, Present and Future, Tourism Recreation Research, Vol.25(1), p.41-58.

Buhalis, D., \& Foerste, M. (2015). SoCoMo marketing for travel and tourism: Empowering cocreation of value. Journal of Destination Marketing \& Management, 4(3), 151-161.

Buhalis, D., \& O'Connor, P. (2005). Information communication technology revolutionizing tourism. Tourism recreation research, 30(3), 7-16.

Buhalis, D., \& Sinarta, Y., (2019), Real-time co-creation and nowness service: lessons from tourism and hospitality, Journal of Travel and Tourism Marketing, Vol. 36(5), pp.563-582.

Chandler, D. (1994). Semiotics for Beginners.

China Internet Network Information Center (2017). Statistical Report on Internet Development in China. Retrieved August 15, 2018, from China Internet Network Information Center Web site: https://cnnic.com.cn/IDR/ReportDownloads/201706/P020170608523740585924.pdf 
China Tourism Academy. (2018). 2017 Outbound Tourism Big Data Report. Retrieved July 14, 2018, from China Tourism Academy Web site: http://www.ctaweb.org/html/2018-2/20182-26-11-57-78366.html

Choo, H., \& Petrick, J. F. (2014). Social interactions and intentions to revisit for agritourism service encounters. Tourism Management, 40, 372-381.

Cohen, E. (1972). Toward a sociology of international tourism. Social research, 164-182.

Cohen, E. (1979a). Rethinking the sociology of tourism. Annals of tourism research, 6(1), 18-35.

Cohen, E. (1979b). A phenomenology of tourist experiences. Sociology, 13(2), 179-201.

Cohen, S. A., Duncan, T., \& Thulemark, M. (2015). Lifestyle mobilities: The crossroads of travel, leisure and migration. Mobilities, 10(1), 155-172.

Cohen, S. A., Prayag, G., \& Moital, M. (2014). Consumer behaviour in tourism: Concepts, influences and opportunities. Current Issues in Tourism, 17(10), 872-909.

Crompton, J. L. (1979). Motivations for pleasure vacation. Annals of Tourism Research, 6(4), 408-424.

Csikszentmihalyi, M., \& Csikszentmihalyi, I. (1975). Beyond Boredom and Anxiety (Vol. 721). San Francisco: Jossey-Bass.

Cushner, K., \& Brislin, R. W. (1996). Intercultural Interactions: A Practical Guide (Vol. 9). Sage Publications.

De Botton, A. (2008). The Art of Travel. Vintage.

Denzin, N. K. (1978). Triangulation: A case for methodological evaluation and combination. Sociological Methods, 339-357.

Dickinson, J. E., Hibbert, J. F., \& Filimonau, V. (2016). Mobile technology and the tourist experience:(Dis) connection at the campsite. Tourism Management, 57, 193-201.

Doty, D. H., \& Glick, W. H. (1994). Typologies as a unique form of theory building: Toward improved understanding and modeling. Academy of Management Review, 19(2), 230-251.

Fan, D. X., Zhang, H., Jenkins, C. L., \& Tavitiyaman, P. (2017). Tourist typology in social contact: An addition to existing theories. Tourism Management, 60, 357-366.

Fast, K., \& Jansson, A. (2019). Transmedia Work: Privilege and Precariousness in Digital Modernity. Routledge.

Flick, U. (2014). An Introduction to Qualitative Research. Sage.

Gibson, H., Willming, C., \& Holdnak, A. (2003). Small-scale event sport tourism: fans as tourists. Tourism Management, 24(2), 181-190.

Hartig, T., \& Staats, H. (2005). Linking preference for environments with their restorative quality. From landscape research to landscape planning: Aspects of integration, education and application, 279-292. 
Higham, J., \& Hinch, T. (2002). Tourism, sport and seasons: the challenges and potential of overcoming seasonality in the sport and tourism sectors. Tourism Management, 23(2), $175-185$.

Huang, W. J., Xiao, H., \& Wang, S. (2018). Airports as liminal space. Annals of Tourism Research, 70, 1-13.

Iso-Ahola, S. E. (1982). Toward a social psychological theory of tourism motivation: A rejoinder. Annals of Tourism Research, 9(2), 256-262.

Jansson, A. (2002). Spatial phantasmagoria: The mediatization of tourism experience. European Journal of Communication, 17(4), 429-443.

Jansson, A. (2007). A sense of tourism: New media and the dialectic of encapsulation/decapsulation. Tourist Studies, 7(1), 5-24.

Jansson, A. (2013). Mediatization and social space: Reconstructing mediatization for the transmedia age. Communication Theory, 23(3), 279-296.

Jansson, A. (2018). Rethinking post-tourism in the age of social media. Annals of Tourism Research, 69, 101-110.

Kaplan, S. (1995). The restorative benefits of nature: Toward an integrative framework. Journal of environmental psychology, 15(3), 169-182.

Kim, J. H. (2015). Understanding narrative inquiry: The crafting and analysis of stories as research. Sage publications.

Kirillova, K., \& Wang, D. (2016). Smartphone (dis) connectedness and vacation recovery. Annals of Tourism Research, 61, 157-169.

Kler, B. K. (2009). Tourism and restoration. Philosophical issues in tourism, 37, 117.

Krippendorf, J. (1986). The new tourist - turning point for leisure and travel. Tourism Management, 7(2), 131-135.

Kushlev, K., \& Proulx, J. D. (2016). The social costs of ubiquitous information: Consuming information on mobile phones is associated with lower trust. PloS One, 11(9), e0162130.

Lash, S. U., \& Urry, J. (1994). Economies of Signs and Space. London: SAGE Publications.

Lehto, X. Y. (2013). Assessing the perceived restorative qualities of vacation destinations. Journal of Travel Research, 52(3), 325-339.

Lincoln, Y. S., \& Guba, E. G. (1985). Naturalistic inquiry (Vol. 75). Sage.

Lovelock, C. H. \& Wirtz, J. (2004). Service Marketing. Englewood Cliffs, NJ, Prentice-Hall.

MacCannell, D. (1976). The tourist: A new theory of the leisure class. University of California Press.

Maoz, D. (2006). The mutual gaze. Annals of Tourism Research, 33(1), 221-239.

Maoz, D. (2010). Warming up peace: An encounter between Egyptian hosts and Israeli guests in Sinai. Tourism, progress and peace, 65-82. 
Marradi, A. (1990). Classification, typology, taxonomy. Quality \& Quantity, 24(2), 129-157.

Mura, P., \& Sharif, S. P. (2017). Narrative analysis in tourism: A critical review. Scandinavian Journal of Hospitality and Tourism, 17(2), 194-207.

Neuhofer, B., \& Ladkin, A. (2017). (Dis) Connectivity in the Travel Context: Setting an Agenda for Research. In Information and Communication Technologies in Tourism 2017(pp. 347359). Springer, Cham.

Nickerson, R. C., Varshney, U., \& Muntermann, J. (2013). A method for taxonomy development and its application in information systems. European Journal of Information Systems, 22(3), 336-359.

Pearce, P. L. (2005). Tourist behaviour: Themes and Conceptual Schemes, Channel View Publications.

Pearce, P. L., \& Lee, U. I. (2005). Developing the travel career approach to tourist motivation. Journal of Travel Research, 43(3), 226-237.

Polkinghorne, D. E. (1995). Narrative configuration in qualitative analysis. International journal of qualitative studies in education, 8(1), 5-23.

Richards, G. (2015). The new global nomads: Youth travel in a globalizing world. Tourism Recreation Research, 40(3), 340-352.

Riessman, C. (2001). Personal troubles as social issues: A narrative of infertility in context. In I. Shaw \& N. Gould (Eds.), Qualitative Research in Social Work (pp. 73-83). London: Sage.

Rihova, I., Buhalis, D., Moital, M., \& Gouthro, M. B. (2015). Conceptualising customer-tocustomer value co - creation in tourism. International Journal of Tourism Research, 17(4), 356-363.

Rossman, G., \& Rallis, S. (2003). Learning in the field: An introduction to qualitative research. Sage.

Ryan, C. (1998). The travel career ladder An Appraisal. Annals of Tourism Research, 25(4), 936957.vv

Smith, V. L. (1989). Hosts and Guests: The Anthropology of Tourism. Philadelphia: University of Pennsylvania Press.

Tanti, A., \& Buhalis, D. (2017). The influences and consequences of being digitally connected and/or disconnected to travellers. Information Technology \& Tourism, 17(1), 121-141.

UNWTO (2017). UNWTO Tourism Highlights, Madrid: UNWTO

Wang, D., Xiang, Z., \& Fesenmaier, D. R. (2016). Smartphone use in everyday life and travel. Journal of Travel Research, 55(1), 52-63.

Weber, M. (1949). Max Weber on the Methodology of the Social Sciences. Free Press.

$\mathrm{Wu}, \mathrm{C}$. (2007). The impact of customer-to-customer interaction and customer homogeneity on customer satisfaction in tourism service - the service encounter prospective. Tourism Management, 28(6), 1518-1528. 
Yu, J., \& Lee, T. (2014). Impact of tourists' intercultural interactions. Journal of Travel Research, 53(2), 225-238. 
Table 1. Demographic Profile of Informants

\begin{tabular}{|c|c|c|}
\hline Content & Numbers & Percentage \\
\hline \multicolumn{3}{|l|}{ Gender } \\
\hline Female & 37 & $73 \%$ \\
\hline Male & 14 & $27 \%$ \\
\hline \multicolumn{3}{|l|}{ Age } \\
\hline $18-24$ & 4 & $8 \%$ \\
\hline $25-29$ & 19 & $37 \%$ \\
\hline $30-39$ & 14 & $27 \%$ \\
\hline $40-49$ & 5 & $10 \%$ \\
\hline $50-59$ & 6 & $12 \%$ \\
\hline 60 or above & 3 & $6 \%$ \\
\hline \multicolumn{3}{|l|}{ Education } \\
\hline High school/diploma & 1 & $2 \%$ \\
\hline College diploma with degree & 4 & $8 \%$ \\
\hline University degree or above & 46 & $90 \%$ \\
\hline \multicolumn{3}{|l|}{ Occupation } \\
\hline Professionals & 14 & $27 \%$ \\
\hline Managers and administrators & 15 & $29 \%$ \\
\hline Clerks & 2 & $4 \%$ \\
\hline Craft and related workers & 2 & $4 \%$ \\
\hline Freelancer & 2 & $4 \%$ \\
\hline Students & 8 & $16 \%$ \\
\hline Retired or hunting for jobs & 8 & $16 \%$ \\
\hline \multicolumn{3}{|c|}{ Household Monthly Income (RMB) } \\
\hline $0-9,999$ & 6 & $12 \%$ \\
\hline $10,000-19,999$ & 6 & $12 \%$ \\
\hline 20,000-39,999 & 22 & $42 \%$ \\
\hline $40,000-79,999$ & 6 & $12 \%$ \\
\hline$\geq 80,000$ & 7 & $14 \%$ \\
\hline N/A & 4 & $8 \%$ \\
\hline \multicolumn{3}{|l|}{ Marital Status } \\
\hline Married without child & 8 & $16 \%$ \\
\hline Married with child(ren) & 19 & $37 \%$ \\
\hline Single & 24 & $47 \%$ \\
\hline \multicolumn{3}{|l|}{ Outbound Travel Frequency } \\
\hline Under 1 time/year & 3 & $6 \%$ \\
\hline 1-2 times/year & 39 & $76 \%$ \\
\hline 3-4 times/year & 8 & $16 \%$ \\
\hline Over 4 times/year & 1 & $2 \%$ \\
\hline
\end{tabular}




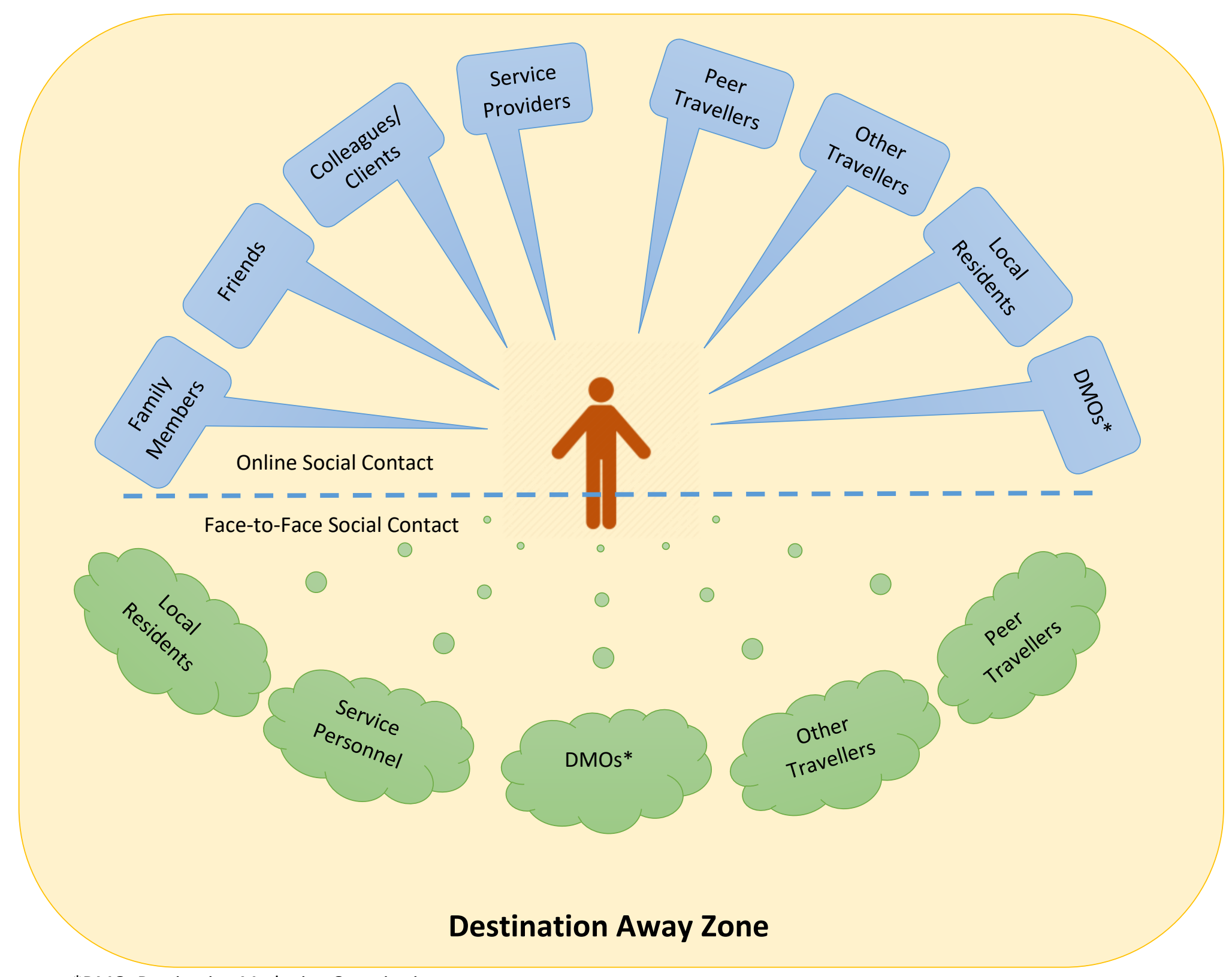

*DMO: Destination Marketing Organisation

Figure 1. Tourist Destination Social Contact in a Connected Era 


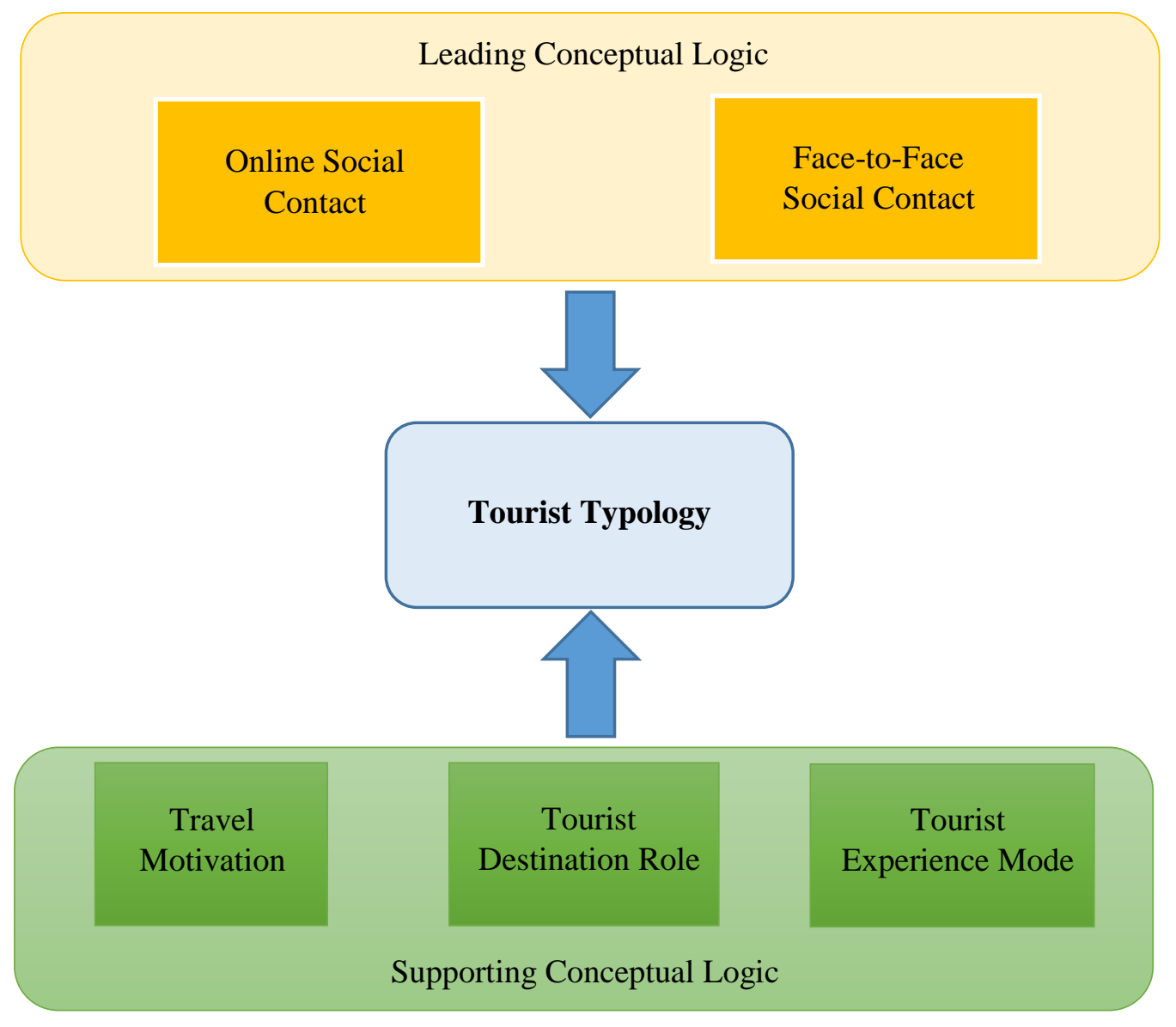

Figure 2. Theoretical Framework of the Study 


\section{Disconnected Immersive Traveller}

Sample: 6

Travel Motivation:

Self-improvement;

Understanding the others;

Experiencing local culture.

Family.

Face-to-face contact:

Other tourists; Service personnel;

Residents.

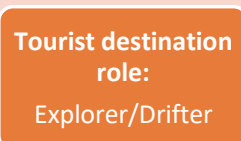

Tourist experience mode:

Experiential/Experime ntal

\section{Digital Detox Traveller}

Sample: 3

Travel Motivation:

Understanding the others;

Experiencing local culture;

Self-reflection;

Emptying oneself; Enhancing companion bond.

Online contact:

Picture posting; Limited.

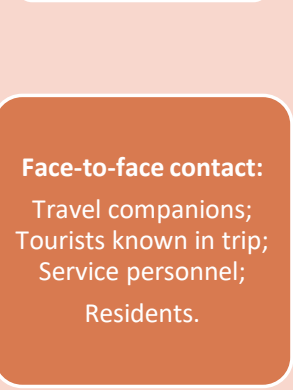

Tourist destination role:

Explorer/Drifter

Tourist experience mode:

Experiential/

Experimental/Exist ential

\section{Diversionary \\ Traveller}

Sample: 12

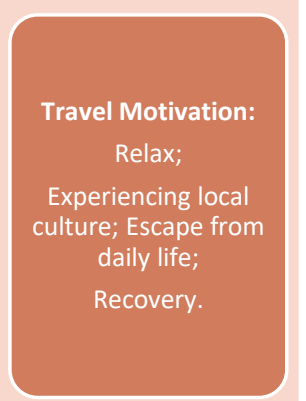

Online contact:

Friends; Family.
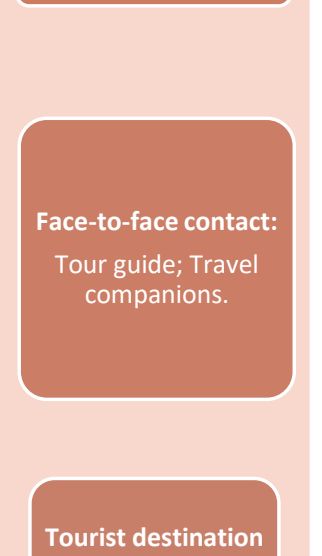
role:

Organized mass

tourist/individual mass tourist

Tourist experience mode:

Diversionary
Dual Zone Traveller

Sample: 14

Travel Motivation:

Relax; Experiencing

local culture; Natural

scenery; Escape from the daily life;

Enhancing companion

bond; Enjoy life;

Cuisine; Understanding the others

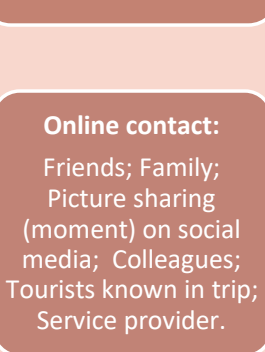

\section{Face-to-face contact:}

Travel companions;

Tour guide; Service

personnel; Residents;

Tourists known in trip;

Local friends and relatives.

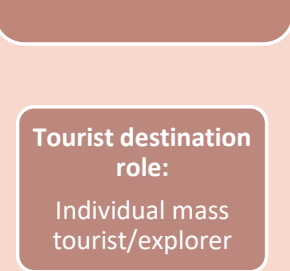

Tourist experience mode:

Experiential/Experi mental
Daily Life Controller

Sample: 8

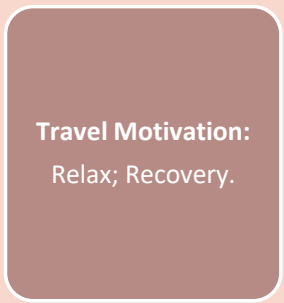

Online contact:

Friends; Family;

Colleagues/clients;

Service provider.

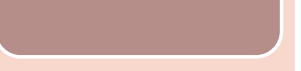

Face-to-face contact:

Tour guide; Service

personnel; Residents;

Travel companions.

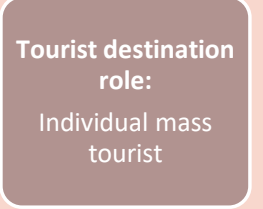

Tourist experience mode:

Recreational
Social Media Addict

Sample: 8

Travel Motivation:

Relax; Recovery;

Experiencing local

culture; Natural scenery.

Online contact:

Friends; Family:

Picture sharing

(moment) on social media.

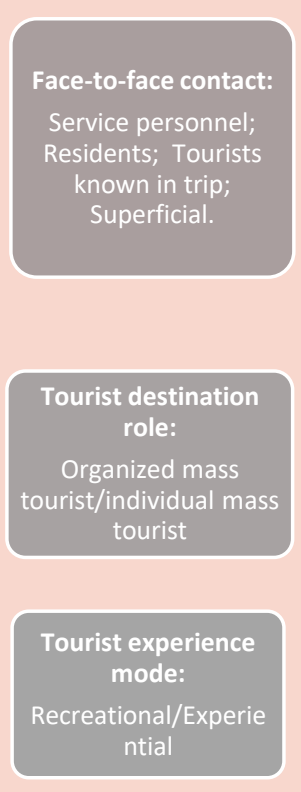

27

Figure 3. Tourist online social contact typology 
Note: Due to the space limit, only salient items in each category are listed.

\section{High Level Online Contact}

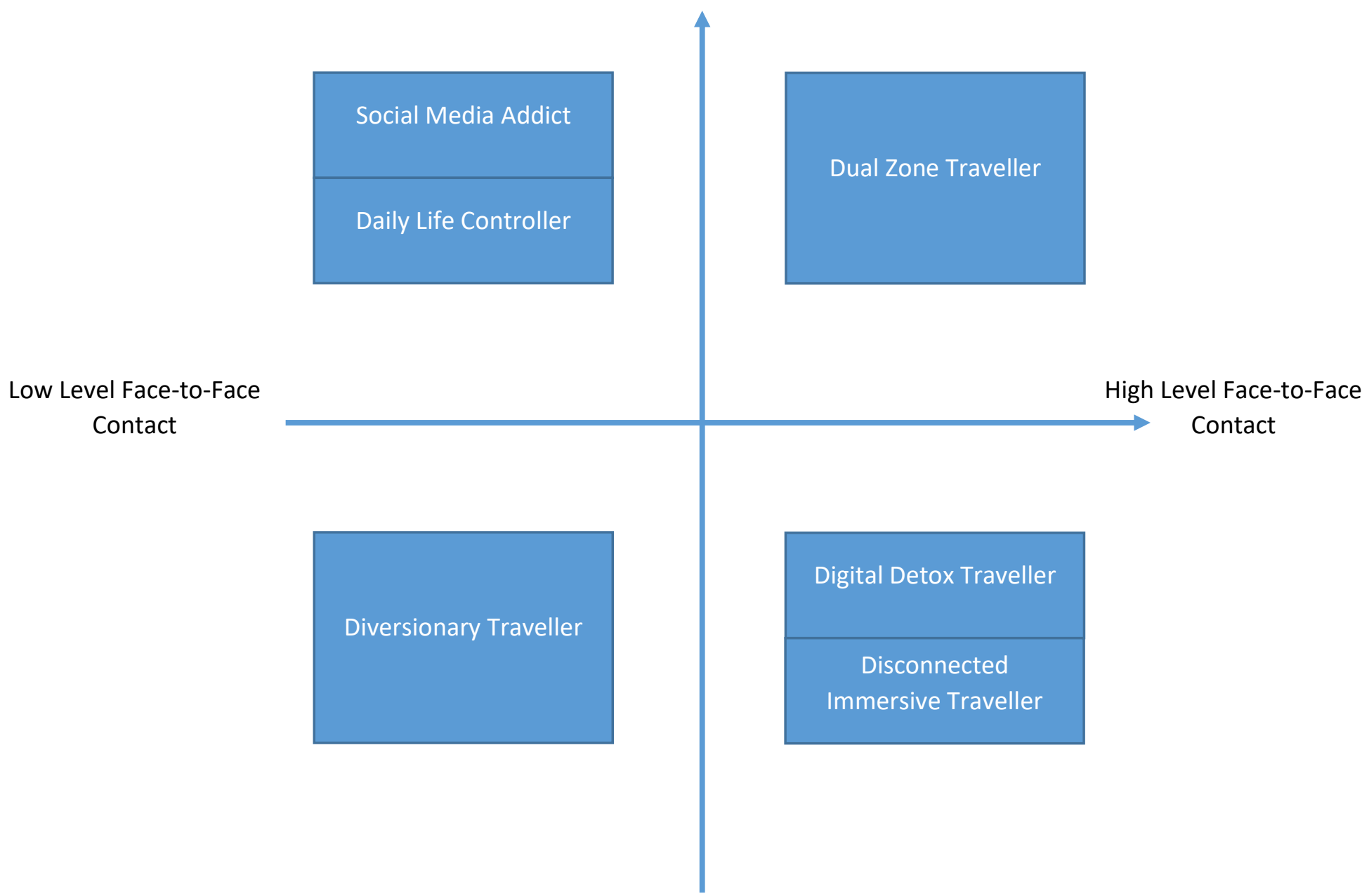

\section{Low Level Online Contact}

Notes: the position of different types only indicates the level of presence in online and face-to-face social contacts and does not show the exact amount and sequence between tourist types within the same quadrant.

Figure 4. Online and Face-to-Face Social Contact Axis 
